\title{
The Use of Dictionary and Contextual Guessing Strategies for Vocabulary Learning by Advanced English-Language Learners
}

\author{
Shufen Huang ${ }^{1} \&$ Zohreh Eslami $^{2}$ \\ ${ }^{1}$ Assistant Professor, Applied English and Foreign Languages, De Lin Institute of Technology, Taiwan \\ ${ }^{2}$ Associate Professor, Texas A\&M University, United States \\ Correspondence: Shufen Huang, Assistant Professor, Applied English and Foreign Languages, De Lin Institute \\ of Technology, Taiwan. E-mail: shufen.hhuang@gmail.com
}

Received: April 1, 2013 Accepted: June 1, 2013 Online Published: July 12, 2013

doi:10.5539/ells.v3n3p1 URL: http://dx.doi.org/10.5539/ells.v3n3p1

\begin{abstract}
The present study provides insight into the use of dictionaries and contextual guessing by advanced English-language learners. This report identifies dictionary use and contextual guessing strategies used by these learners most often and least often. Participants were 100 international graduate students at a large southwestern U.S. university who completed a vocabulary learning strategy questionnaire. The results indicated that these learners consulted a dictionary most often to find out the pronunciation of a new word and least often to learn the frequency of use and appropriate usage of an unknown word. Participants most often based their guesses of a word's meaning from the paragraph's main ideas and background information. Using the meaning of individual parts of an unfamiliar compound word (such as note-book) and the part of speech of a new word were the least-used guessing strategies.
\end{abstract}

Keywords: ESL, advanced English-language learners, vocabulary learning strategies, dictionary use, contextual guessing

\section{Introduction}

Schmitt (2000) suggests that language learners need a vocabulary size of 2,000 word families to maintain a conversation, and at least 10,000 word families for reading comprehension of academic texts. These large vocabulary sizes are challenging for language learners to master. Unsurprisingly, therefore, second-language learners perceive vocabulary acquisition as one of their greatest difficulties and the area they most desire to master. Schmitt (2000) suggests that vocabulary learning strategies are a means of enhancing vocabulary learning. Learners can use several strategies, such as using a dictionary, receiving help from the teacher or peer, or parsing the meaning of a word from its context, to facilitate the learning of new words (Harley \& Hart, 2000; Qian, 2004). Among these strategies, dictionary use and guessing strategies are widely used. Poorer language learners benefit from the vocabulary learning strategies of advanced language learners to improve their success record. Thus, the current investigation attempted to provide insight into this issue by providing a better understanding of advanced English language learners' strategies pertaining to dictionary use and contextual guessing.

\section{Review of Literature}

As mentioned, language learners need to acquire considerable vocabulary to succeed in English-language learning. This makes it impossible for learners to acquire all the necessary vocabulary explicitly; therefore, incidental vocabulary learning is required. When language learners encounter unknown words in reading, they can look up or infer their meaning. Two common strategies were widely used to unlock the meaning of unknown words: dictionary use and contextual guessing. Looking up the meaning of unknown words increases in-depth comprehension of a particular text and the precision of the words in a given context. Inferential guessing is essential in second-language learning.

\subsection{Dictionary Use}

A single word may have several possible meanings, and the appropriate one can often be determined based on context. Laufer (1990) believes that a word in a sentence could look familiar to language learners; however; they may find that this meaning in the given sentence makes no sense. In addition, guesses of the meaning of an 
unknown word are rarely accurate. Kaivanpanah and Alavi's (2008) study confirms that learners' inferences about the meaning of unfamiliar vocabulary are not always reliable. Thus, advocates of dictionary use suggest that teachers should encourage learners to use a dictionary to find the particular meaning of an unfamiliar word in a given context. Dictionaries are the essential source for information about words in a language (Walz, 1990). Hayati and Fattahzadh (2006) also recommend that learners consult a dictionary for the meaning of an unfamiliar word to make certain that their assumptions are accurate based on the contextual information. Access to a dictionary helps learners become more autonomous because they can find appropriate interpretations of unfamiliar words in sentences without depending on teachers' explanations (Gu 2003; Miyanaga, 2006).

\subsection{Types of Dictionaries}

Different types of dictionaries (monolingual and bilingual) have their own distinct advantages. Although a monolingual dictionary generally provides more in-depth explanations pertaining to the function of vocabulary in context (Albus et al., 2005), it requires a large amount of vocabulary and grammatical knowledge to understand the meaning of an unknown word. On the other hand, a bilingual dictionary supplies meaning in an accessible fashion, which can be bi-directional (i.e., English to first language and first language to English) (Nation, 2001). Some studies (Qian, 2004; Wei, 2007) reveal that English-language learners prefer a bilingual dictionary to a monolingual dictionary. For example, Qian's (2004) study found that the majority of students with intermediate language proficiency consulted a bilingual dictionary when confronted with unfamiliar words. Wei's (2007) study also showed that the use of an English-Chinese dictionary was more favored than that of English-English dictionaries by Chinese college students.

Even though many prefer bilingual dictionary use, some researchers (Baxter, 1980; Nation, 2001) point out that this type of dictionary has several drawbacks. A bilingual dictionary tends to lead students to depend on a one-to-one correspondence of words between the meaning of an unknown word in the second language and translation in their first language (Baxter, 1980; Nation, 2001). Baxter's (1980) study showed that Japanese learners rely greatly on bilingual dictionaries, which may discourage them from using communication strategies in oral activities. Unlike monolingual dictionaries that supply conversational definitions, bilingual dictionaries tend to provide a single lexical item for meaning.

\subsection{Contextual Guessing}

A language learner reads most words in text as sight words and uses information in text to unlock the meaning of unknown words (Gaskins, 2004). Contextual guessing strategies are commonly used to infer the meaning of unfamiliar words in situations when language learners have a lack of knowledge in vocabulary, grammar, or other linguistic elements to read a given text. According to Oxford (1990), contextual guessing strategies can be made based on a wide range of clues; namely, linguistic and nonlinguistic clues. Language learners establish the meaning of a new word based on interpretation of its immediate text, which is one or two words before or following the unknown word. Learners also use other linguistic clues, such as semantic or syntactic knowledge to unlock the meaning of new words. With regard to nonlinguistic clues, language learners apply the knowledge of context, text structure, and general world knowledge (Oxford, 1990).

In a similar vein, Nagy (1995) suggests that the effects of contextual guessing are determined by language learners' knowledge of linguistics, strategies, and the world. Linguistics knowledge includes knowledge with regard to syntax, word schemas, and vocabulary. The meaning of a word determines its syntactic behavior. Likewise, the syntactic behavior of a word in text provides important information concerning its word meaning. Language learners with strong syntactic knowledge tend to accurately infer the meaning of unknown words; the context constrains the possible meanings for a given word in text. Knowledge of the words surrounding an unknown word helps language learners infer the meaning of the words in context. Learners can guess the meaning of the unknown words based on the schema created by the words. Vocabulary also provides learners with information regarding the words using their affixes to predict its meaning. For instance, the words "dictionary", "predict", and "diction" share the same affix, "dict". With the knowledge about the affix, language learners can easily and accurately predict the meaning of the word. Strategic knowledge is defined as conscious control over cognitive resources, which enables language learners to effectively unlock and gain better retention of the meaning of unknown words. World knowledge gives learners the context to select the appropriate meaning of a word or to infer the meaning of an unfamiliar word in a given context. Learning a word from context requires matching to familiar concepts, which brings in the concept of world knowledge.

Although dictionary use can enhance the accuracy and precision of the meaning of unknown words, it slows learners' reading comprehension (Knight, 1994). Thus, some teachers encourage students to guess the meaning of an unknown word from its context and to refer to a dictionary only as a last resort. According to Nation (2001), 
learning vocabulary via guessing from context is the most important of all sources of vocabulary learning. Many educators encourage the contextual guessing strategy, which refers to the use of background knowledge and linguistics cues to infer the meaning of unknown words (Kaivanpanah \& Alavi, 2008). Parel (2004) found that although reading comprehension results from receptive vocabulary knowledge, the ability to use inferencing strategies improves the reading skills of language learners with low receptive vocabulary. Paribakht's (2004) study highlighted how learners frequently use their background knowledge to enhance the accuracy of guessing the meaning of unknown words. If the topic or main idea of the text is familiar, learners have a greater possibility of correctly guessing the meaning of unknown word. Fischer (1994) contends that students who infer the meaning of an unfamiliar word generate their own equivalent meaning based on contextual cues. In addition, a dictionary provides a decontextualized meaning (Rhoder \& Huerster, 2002). Therefore, students often have difficulty developing an appropriate context for an unfamiliar word based on dictionary definitions.

\section{Statement of the Problem}

Many researchers have conducted studies on the frequency of use of vocabulary learning strategies vis-à-vis dictionary use and/or contextual guessing with a focus on learners at the beginning or intermediate proficiency level (Fan, 1998, 2003; Harley \& Hart, 2000; Hayati \& Fattahzadh, 2006; Loucky, 2002; Qian, 2004). Findings from the research generally corroborate that language learners more often guess a word's meaning from its context rather than by consulting a dictionary. Knight (1994) found that learners who consulted a dictionary learned more vocabulary in both immediate and delayed tests than those who did not. Moreover, students with low vocabulary ability benefited the most from dictionary use. Barnett (1989) found that advanced language learners demonstrated more guessing strategy use than did intermediate learners. Compared with their intermediate counterparts, advanced learners guessed more because they had sufficient vocabulary knowledge to do so. Therefore, with the basis of the context created by known vocabulary, advanced learners can more successfully guess the meaning of unfamiliar words. Kaivanpanah and Alavi (2008) assert that the correctness of learners' guessing is highly related to their language proficiency. The more proficient students are, the more likely they are to guess unknown words accurately. In addition, they use a bilingual dictionary more often than a monolingual dictionary. Fan (2003) suggests that learners with low English proficiency may benefit greatly when they see the relevance of strategy use in L2 vocabulary development. These learners also can benefit from the introduction to the strategies applied often by proficient vocabulary learners. However, advanced learners' vocabulary learning strategies have not been sufficiently investigated. In an attempt to bridge this gap, the purpose of the present study was to investigate advanced ESL learners' vocabulary learning strategies concerning dictionary use and contextual guessing.

\section{Methodology}

\subsection{Participants}

A total of 100 international graduate students (53 males and 47 females) at a large Southwestern U.S. university voluntarily participated in this study. These students were from fairly diverse linguistic backgrounds: Chinese (Mandarin), Taiwanese, Korean, Japanese, Turkish, and Indonesian. They came from a wide array of disciplines, such as education, English, mechanical engineering, business, and public health. They had studied English for a mean of 17.6 years $(\mathrm{SD}=4.6)$ and had studied English in a native-English-speaking country for an average of 3.3 years. The participants ranged from 26 to 30 years of age.

\subsection{Instrument}

In the current investigation, the questionnaire consisted of two sections. The first section investigated participants' backgrounds regarding their major, first language, years of English study, and years of study in a native-English-speaking country. The second section, adopted from Fan's (2003) study, included 18 items of vocabulary-learning strategies divided into two categories (guessing strategy and dictionary use strategy). These items explored the frequency of use pertaining to vocabulary-learning strategies on a 5-point Likert scale ranging from never to very often.

\section{Procedure}

Participants were informed of the purpose of this study, agreed to participate, and signed a consent form. The vocabulary-learning questionnaire was administered to the 100 international students in spring 2008. The participants filled out the questionnaire at the campus library.

\subsection{Data Analysis}

Cronbach's Alpha reliability for the strategy section of the questionnaire was .86. This provided evidence of the commonalities of responses across the questions. The construct validity of the questionnaire was investigated by 
means of exploratory factor analysis (EFA) to determine strategy grouping that might be helpful in determining potential constructs underlying the 18 strategy items. Descriptive analysis was also used to determine any overall patterns of vocabulary-learning strategies by these advanced learners beyond common themes. Moreover, the frequency of use of individual vocabulary learning strategies was examined to provide a descriptive baseline for this group.

\section{Results}

Items 1 through 12 explored the frequency with which students use a dictionary strategy, while items 13 through 18 investigated the frequency of use of guessing strategies. The descriptive analysis of all strategies is listed in Table 1.

Table 1. Descriptive analysis of the frequency use of the vocabulary learning strategies

How frequently do you use it?

$1=\mathrm{I}$ never use the strategy stated;

$2=$ I seldom use the strategy stated;

$3=\mathrm{I}$ occasionally use the strategy stated;

$4=$ I often use the strategy stated;

$5=\mathrm{I}$ very often use the strategy stated.

\begin{tabular}{|c|c|c|}
\hline & M & SD \\
\hline \multicolumn{3}{|l|}{ Item } \\
\hline \multicolumn{3}{|l|}{ When I use a diction ary, I look for/ check } \\
\hline 1 an English dictionary & 3.30 & 1.28 \\
\hline 2 a bilingual dictionary & 3.24 & 1.42 \\
\hline 3 the English definition of the new word & 3.51 & 1.07 \\
\hline 4 the pronunciation of the new word & 3.83 & 0.93 \\
\hline 5 all the meanings of the new word & 3.04 & 1.11 \\
\hline 6 the contextual meaning of the new word & 3.80 & 1.01 \\
\hline 7 the part of speech of the new word & 3.27 & 1.10 \\
\hline 8 the derived forms of the new word, e.g., inform/ information & 3.30 & 1.08 \\
\hline 9 the grammatical patterns of the new word, e.g., interested in, like to go & 3.52 & 1.05 \\
\hline 10 the collocational patterns of the word, e.g. dog's bark & 3.06 & 1.08 \\
\hline 11 the frequency of the word, i.e., whether it is a common or rare word & 2.68 & 1.20 \\
\hline 12 the appropriate usage of the word, e.g., forma/ informal usage & 2.84 & 1.18 \\
\hline \multicolumn{3}{|l|}{ While guessing, I use } \\
\hline 13 the part of speech of the new word & 3.42 & 1.13 \\
\hline 14 the meaning of different parts of the new word, e.g., note-book & 3.26 & 1.14 \\
\hline 15 the relationship between the new word and other words in the sentence & 3.59 & 1.16 \\
\hline $\begin{array}{l}16 \text { the relationship between the sentence the word is in } \\
\text { and other sentences in the paragraph by linking words, e.g., however, firstly, etc. }\end{array}$ & 3.55 & 1.08 \\
\hline 17 the main idea of the passage & 3.92 & 0.87 \\
\hline 18 my expereince and common sense & 3.76 & 1.00 \\
\hline
\end{tabular}

\subsection{Factor Analysis}

An exploratory factor analysis (EFA) was performed to detect underlying constructs of the 18 items. Principal component analysis with Promax rotation was conducted, and two factors were extracted. Loadings of variables on factors, communalities, and percents of the variance are shown in Table 2. The solution accounted for $46.8 \%$ of the total variances. Items 1 through 12 were loaded on the first factor, which was assigned the label 'Dictionary Use'. Factor 1 accounted for $33.6 \%$ of the total variance. Items 13 through 18 were loaded on factor two, which was labeled 'Contextual Guessing'. Factor 2 accounted for $13.2 \%$ of the total variance. 
Table 2. Factor loadings, communality, percents of variance for two-factor principal component analysis with Promax rotation

\begin{tabular}{lccc}
\hline Label & \multicolumn{3}{c}{ Dictionary Use Contextual Guessing } \\
\hline Item & Factor 1 & Factor 2 & Communality \\
\hline Item 1 & .61 & & .30 \\
Item2 & .64 & .33 \\
Item3 & .78 & & .50 \\
Item4 & .35 & & .29 \\
Item5 & .57 & .38 \\
Item6 & .67 & & .45 \\
Item 7 & .46 & & .64 \\
Item8 & .57 & & .56 \\
Item9 & .52 & & .49 \\
Item10 & .76 & & .58 \\
Item11 & .71 & & .46 \\
Item12 & .75 & & .46 \\
Item13 & & .78 & .63 \\
Item14 & & .69 & .54 \\
Item15 & & .81 & .69 \\
Item16 & & .78 & .56 \\
Item17 & & .58 & .32 \\
Item18 & & .55 & .25 \\
\% of & 33.6 & 13.2 & \\
Variance & & & 46.8 \\
\% of total variance & & \\
\hline
\end{tabular}

\subsection{Dictionary Use Strategy}

The mean of monolingual dictionary use (Item $1 ; \mathrm{M}=3.30, \mathrm{SD}=1.28$ ) was higher than that of bilingual dictionary use (Item 2; $\mathrm{M}=3.24, \mathrm{SD}=1.42$ ). However, the result of a dependent t-test showed no statistically significant difference between monolingual and bilingual dictionary use $(t=.29, d f=99, p=\mathrm{n} . \mathrm{s}$.). As shown in Table 1, the participants demonstrated frequent use of a dictionary to learn the pronunciation of a new word (Item $4 ; M=3.83$, $\mathrm{SD}=.93$ ) as well as to learn its contextual meaning (Item $6 ; \mathrm{M}=3.80, \mathrm{SD}=1.01$ ). In addition, the results showed that the students often consulted a dictionary to learn the grammatical patterns of a new word (Item $9 ; \mathrm{M}=3.52$, $\mathrm{SD}=1.05$ ) and to learn the English definition of a new word (Item 3; $\mathrm{M}=3.51, \mathrm{SD}=1.07$ ). Furthermore, the students did not often use a dictionary to learn derivations of the new word, such as 'inform' and 'information' (Item8; $\mathrm{M}=3.30, \mathrm{SD}=1.08$ ). The students also showed that they used a dictionary less to learn all the meanings of a new word (Item 5; M=3.04, $\mathrm{SD}=1.11$ ) or its part of speech (Item 7; M=3.27, SD=1.10). The students indicated that they seldom used a dictionary to learn the appropriate usage of a word (Item 12; $\mathrm{M}=2.84, \mathrm{SD}=1.18$ ), and they used a dictionary the least to learn the frequency of a word: whether it is often or rarely used (Item $11 ; \mathrm{M}=2.68$, $\mathrm{SD}=1.20)$.

\subsection{Contextual Guessing Strategy}

Considering the main idea of the passage while guessing received the highest score among the contextual guessing strategies. Participants reported that they occasionally use the main idea of a passage (Item 17; M=3.92, $\mathrm{SD}=.87$ ) while inferring the meaning of an unknown word from its context. The students also indicated that they often use their experience and common sense to guess the meaning of unfamiliar words (Item $18 ; \mathrm{M}=3.76, \mathrm{SD}=$ 1.00). The students reported that they occasionally used the meanings of components of an unfamiliar word, such as note-book, to guess the meaning of the word (Item $14 ; \mathrm{M}=3.26, \mathrm{SD}=1.14$ ). The students also responded that they do not often look at the part of speech of a new word to guess the meaning (Item 13; $\mathrm{M}=3.42, \mathrm{SD}=1.13$ ). Items 15 to 18 relate to vocabulary context. Students reported that they occasionally used the following strategies: "The relationship between the new word and other words in the sentence" (Item 15, M=3.59, SD=1.16) and "The relationship between the sentence the word is in and other sentence in the paragraph by linking words: e.g. nevertheless, however, first, etc." (Item 16, M=3.55, SD=1.08). 


\section{Discussion and Conclusion}

This study aimed to explore which vocabulary learning strategies concerning dictionary use and contextual guessing are used most and least frequently by advanced language learners studying at the university level. Among the dictionary use strategies, most of the time these students consulted a dictionary to learn the pronunciation of a new word. This finding highlights the importance of dictionary use in decoding, or the accuracy of sounding the words out in English. Conversely, they used a dictionary the least for information concerning the frequency and the appropriate usage of an unknown word. The lowest mean value of 2.68 was found in item 11 "When I use a dictionary, I use the frequency of the word, i.e., whether it is a common or rare word." Another low mean value of 2.84 was found in item 12, "When I use a dictionary, I use the appropriate usage of the word, e.g., formal/informal usage." A possible reason for respondents' reluctance to use a dictionary might be the fact that this information was not directly linguistics-related.

These advanced learners most often used the main idea and background information to formulate their guesses. They made heavy use of contextual cues for guessing, such as the relationship between the new word and other words in the sentence, and the relationship between the sentence's word and conjunction. The finding suggests that language learners have a deeper understanding of the meaning of unfamiliar words if they are familiar with the main idea of the text. The highest mean value of 3.92 was found in item 17, "While guessing, I use the main idea of the passage." The result confirmed the importance of the main idea of text in vocabulary learning. These findings were consistent with those from previous research (Nassaji, 2003; Paribakht, 2004), and highlighted the importance of the global context in contextual guessing. Teachers should encourage language learners to take advantage of the main idea of text to unlock the meaning of unfamiliar words. These learners, on the other hand, occasionally guessed the meaning of an unknown word by applying item 14, "While guessing, I use the meaning of different parts of the new word, i.e., note-book. Occasionally, they also applied item 13, "While guessing, I use the part of speech of the new word. However, the mean values of items 13 and 14, which investigated the importance of word-component, were not considerably lower than those of item 17, which explored the significance of the global context. A possible explanation for these findings is that vocabulary learning strategies of contextual guessing concerning word-component and global context both play a vital role in vocabulary development.

\section{Suggestion for Future Studies}

Further research can duplicate the present study with a larger sample size. In a large-scale study, data can produce a more robust analysis and help researchers draw more generalizable conclusions. In addition, further studies can expand the present study by observing these learners' reading behavior and vocabulary acquisition tasks to validate students' self-reported vocabulary learning strategies. Meanwhile, a think-aloud procedure can provide a better understanding of how learners generate the meaning of a word and which vocabulary learning strategies they apply without intrusion on reading. Although the self-reported data in this study provide valuable information regarding advanced learners' vocabulary learning strategies, the observation data of the think-aloud procedure can help verify which strategies the students employed as they engaged in vocabulary acquisition tasks.

The total explained variance by factors 1 and 2 was $46.8 \%$; therefore, other aspects that may affect dictionary use or contextual guessing need to be explored. For example, items of dictionary use associated with comprehension need to be added, such as looking up a word that is essential to comprehend a sentence or paragraph or when not knowing a word prevents understanding an entire sentence or paragraph. On the other hand, all items appeared to relate primarily to the theoretically derived constructs under which the original questionnaire was derived, providing good evidence for the construct validity of both the instrument and the responses of a widely varying group of advanced English language learners.

\section{References}

Albus, D., Thurlow, M., Liu, K., \& Bielinski, J. (2005). Reading test performance of English-language learners using an English dictionary. The Journal of Educational Research, 98(4), 245-254. http://dx.doi.org/10.3200/JOER.98.4.245-256

Barnett, M. (1989). More than meets the eye. Englewood Cliffs, NJ: Prentice Hall.

Baxter, J. (1980). The dictionary and vocabulary behavior: A single word or a handful. TESOL Quarterly, 3, 325-336.

Fan, M. (1998). An investigation into the problem of recording technical vocabulary. Asia-Pacific Journal of Teacher Education and Development, 1(1), 83-92. 
Fan, M. (2003). Frequency of use, perceived usefulness, and actual usefulness of second language vocabulary strategies: A study of Hong Kong learners. The Modern Language Journal, 87(2), 222-241. http://dx.doi.org/10.1111/1540-4781.00187

Fischer, U. (1994). Learning words from context and dictionary: An experimental comparison. Applied Psycholinguistics, 15, 551-574. http://dx.doi.org/10.1017/S0142716400006901

Gaskins, I. (2004). Word detectives. Educational Leadership, 61(6), 70-73.

Harley, B., \& Hart, D. (2000). Vocabulary learning in the content-oriented second language classroom: Student perceptions and proficiency. Language Awareness, 9, 78-96. http://dx.doi.org/10.1080/09658410008667139

Hayati, M., \& Fattahzadh, A. (2006). The effect of monolingual and bilingual dictionaries on vocabulary recall and retention of EFL learners. The Reading Matrix, 6(2), 125-134.

Miyanaga, C. (2006). Anxiety, strategies, motivation, and reading proficiency in Japanese university EFL learners. Unpublished doctoral dissertation, Temple University, Philadelphia.

Nagy, W. (1995). On the role of context in first- and second-language vocabulary learning. Technical report. No. 627. Center for the study of reading, Urbana, IL.

Nassaji, H. (2003). L2 vocabulary learning from context: Strategies, knowledge sources, and their relationship with success in L2 lexical inferencing. TESOL Quarterly, 37(4), 645-670. http://dx.doi.org/10.2307/3588216

Nation, P. (2001). Learning vocabulary in another language. New York: Cambridge University Press.

Kaivanpanah, S., \& Alavi, M. (2008). Deriving unknown word meaning form context: Is it reliable? RELC Journal, 39(1), 77-95. http://dx.doi.org/10.1177/0033688208091141

Knight, S. (1994). Dictionary use while reading: The effects on comprehension and vocabulary acquisition for students of different verbal abilities. The Modern Language Journal, 78, 285-298. http://dx.doi.org/10.1111/j.1540-4781

Laufer, B. (1990). Ease and difficulty in vocabulary learning: Some teaching implications. Foreign Language Annals, 23(2), 147-155. http://dx.doi.org/10.1111/j.1944-9720

Loucky, J. (2002). Improving access to target vocabulary using computerized bilingual dictionary. ReCALL, 14 , 293-312. http://dx.doi.org/10.1017/S0958344002000721

Oxford, R. L. (1990). Language learning strategies: What every teacher should know. Boston: Newbury House.

Parel, R. (2004). The impact of lexical inferencing strategies on second language reading proficiency. Reading and Writing: An Interdisciplinary Journal, 17, 847-873. http://dx.doi.org/10.1007/s11145-004-9347-6

Paribakht, T. (2004). The role of grammar in second language learning processing. RELC, 35(2), 149-160.

Qian, D. (2004). Second language lexical inferencing: preferences, perceptions, and practices. In P. Bogaards, \& B. Laufer (Eds.), Vocabulary in a second language: selection, acquisition, and testing (pp. 155-169). Philadelphia: John Benjamins Publishing Company.

Rhoder, C., \& Huerster, P. (2002). Use dictionaries for word learning with caution. Journal of Adolescent and Adult Literacy, 45(8), 730-735.

Schmitt, N. (2000). Vocabulary in language teaching. New York: Cambridge University Press.

Walz, J. (1990). The dictionary use as a secondary source in language learning. The French Review, 64(1), 79-94.

Wei, M. (2007). An examination of vocabulary of college-level learners of English in China. Asian EFL Journal, 93-114.

\section{Copyrights}

Copyright for this article is retained by the author(s), with first publication rights granted to the journal.

This is an open-access article distributed under the terms and conditions of the Creative Commons Attribution license (http://creativecommons.org/licenses/by/3.0/). 